\title{
Identify Toxin Contamination in Peanuts Using the Development of Machine Vision Based on Image Processing Technique
}

\author{
Atris Suyantohadi ${ }^{* 1}$, Rudiati Evi Masithoh ${ }^{2}$ \\ ${ }^{1}$ Department of Agroindustrial Technology, Faculty of Agricultural Technology, \\ Universitas Gadjah Mada, Jl Flora 1 Bulaksumur 55281, Indonesia \\ ${ }^{2}$ Department of Agicultural Engineering, Faculty of Agricultural Technology \\ Universitas Gadjah Mada, Jl Flora 1 Bulaksumur 55281, Indonesia \\ Email: atris@ugm.ac.id*
}

\begin{abstract}
This research aimed at identifying the use of image processing technique and classifying the use of K-mean clustering of contaminated and uncontaminated peanuts. A machine vision system was made of a small aluminum box, equipped with a camera, a petri for placing the sample, USB connector, UV lamp, and a computer. Image processing methods consisted of analysis of the average color of RGB in the region of interest, convertion of RGB into HSV, segmentation process, as well as convertion image into grayscale and binary objects in order to obtain the total number of pixels value in the object area so that the mean value of the pixels of the area can be calculated. K-means algorithm was used to classify the contaminated and uncontaminated peanuts based on the average pixel value of $R, G, B$ color parameters. The accuracy of a system was $100 \%$ meaning that the performance of machine vision can be used to identify the contaminated and uncontaminated peanuts.
\end{abstract}

Keywords: aflatoxin, K-mean clustering, machine vision, image processing, peanuts

\section{INTRODUCTION}

Aflatoxin contamination in agricultural products, such as cereals and nuts, affected from pre-harvest, harvest and post-harvest handling. Aflatoxin contamination in postharvest agricultural products both at farmers, collectors and traders showed a value that exceeds the threshold of food security. The high aflatoxin contamination will adversely affect health and not be able to meet food safety standards.

Computer vision technology such as a machine vision is able to replace human perception using computer devices which is easily adapt to the environment, to retrieve and process data, to give the reaction process, and to learn based on the learning experience to increase the performance (Sebe, et al, 2005; $\mathrm{Lu}, 1993)$.

Development of machine vision that works based on digital image processing of a captured images by a digital camera has significantly increase and gained success in various applications such as identification, detection, classification, and segmentation of agricultural materials. This method can speed up the time of analysis, has low cost, and is carried out non-destructively without damaging the samples.

Non-destructive detection of microbes and bacteria using digital image processing has gained success in its application. Detection of pathogenic bacteria in Escherichia coli DNA Slide Microarrays using automated image analysis algorithms and classification has an error rate of $1.4 \%$ of the samples test (Haff, et al, 2010). Using photoacoustic spectroscopic and pattern classification technique using neural network, Gordon (2009) was able to detect level of fungal contamination in food. Detection of fertility level that occurs in eggs to reduce the risk level of hatching failure has been done by Faridah, et al (2008) using a machine vision. The embryo development is unable to see by naked eyes. Therefore, a digital camera was 
modified having a gray level between the 23 to 43 in order to detect the embryo fertility in the eggs which in turn reached $92.36 \%$ accuracy. Aflatoxin contamination in the distribution chain of corn-based food products using TLC was conducted by Kusumaningrum, et al (2010). The TLC method analyzed in the laboratory showed that $20 \%$ of the samples had contamination level greater than 20ppb. Using ultraviolet light and a digital camera Lowe, et al (2003) was capable of detecting the presence of scorpions. This research aimed at developing a machine vision tools to detect non-destructive aflatoxin contamination in peanuts after harvest.

\section{MATERIAL AND METHODS}

\subsection{Samples}

The samples consisted of aflatoxin contaminated and uncontaminated peanuts taken from farmers in Sleman Yogyakarta which have been classified by experience peanut vendors. Peanuts having higher than 20 ppb of aflatoxin were categorized as aflatoxincontaminated peanuts. Fig. 1 shows samples of uncontaminated and contaminated peanuts. Total samples were 48 seed images consisting of aflatoxin contaminated and uncontaminated peanuts. Image processing and analysis will then be done to classify peanuts based on contaminated cluster and uncontaminated cluster.

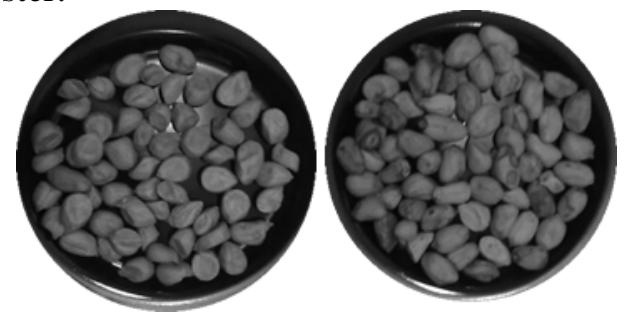

Figure 1 Uncontaminated and contaminated peanuts

\subsection{Development of machine vision technology}

Machine vision mimics the workings of human visual system which is very complex. People look at the object with the eyes. The object image was then transmitted to the brain to be interpreted so that people understand what the object is. The results of this interpretation may be used for decision making. Machine vision is an automated process that integrates a large number of processes for visual perception, such as image acquisition, image processing, classification, recognition, and decision (Bigun, 2006). Machine vision consists of techniques to estimate the characteristics of objects in the image, to measure object geometry, and to interpret information geometry. Machine vision process comprises three main activities: 1) image capturing, 2) image processing, 3) image analyzing.

In this research, the machine vision system consisted of a computer and a box having dimension of $23 \times 40 \times 16 \mathrm{~cm} 3$ with a 2-megapixel resolution web camera, object apparatus, and 2 of $8 \mathrm{~W}$ UV light attached to it. Fig. 2 shows the machine vision system developed in this research.

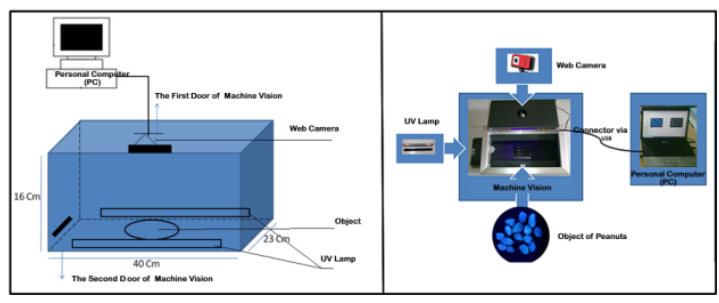

Figure 2 Machine vision system developed in this research

\subsection{Development of image processing program}

Design of application programs was compiled using the Matlab and Image Processing ToolBox. Image processing methods consisted of analysis of the mean color of RGB (Red Green Blue) in the region of interest, convertion of RGB into HSV (Hue Saturation Value), segmentation process, as well as convertion image into grayscale and binary objects in order to obtain the total number of pixels value in the object area so that the mean value of the pixels of the area can be calculated. RGB components were obtained directly from the color image, while the index of each component was obtained after the normalization process as follows:

$$
\begin{aligned}
r & =\frac{R}{R+G+B} \\
g & =\frac{G}{R+G+B} \\
b & =\frac{B}{R+G+B}
\end{aligned}
$$


The conversion of RGB images, which each has a value matrix of $r, g$ and $b$, into gray-scale images which has a value of $\mathrm{s}$, can be done by taking the average of the values of $\mathrm{r}, \mathrm{g}$ and $\mathrm{b}$, as follows:

$$
s=\frac{r+g+b}{3}
$$

The conversion of color images into grayscale was done by using the average grayscale value of each layer of $R, G$, and $B$, as follows:

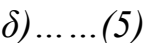

Grayscale $=\alpha R+\beta G+\delta B /(\alpha+\beta+$ with $\alpha=0.35, \beta=0.25$ and $\delta=0.4$ so that $\alpha+\beta+\delta=1$

To capture image having various RGB color on its background, conversion need to be done to get a high saturated color. Conversion of RGB color into HSV format was done as follows:

$$
\begin{aligned}
V & =\max (R, G, B) \\
\delta & =V-\min (R, G, B) \\
s & =\frac{\delta}{V}
\end{aligned}
$$

To get Hue $(\mathrm{H})$ values do the following statement:

if $\mathrm{R}=\mathrm{V}$, then $H=1 / 6(G-B) / \delta$,

if $\mathrm{G}=\mathrm{V}$, then $H=1 / 6(2+(B-R / \delta)$,

if $\mathrm{B}=\mathrm{V}$, then $H=1 / 6(4+(R-G / \delta)$.

\subsection{Classification method using K-means}

To differentiate between uncontaminated and contaminated objects, classification analysis was performed using k-means algorithm. K-Means is a method of analyzing the data to classify object without training (unsupervised learning). Object classification is done by the partition system. K-means clustering method attempts to minimize variations among the data in a group (cluster) and to maximize the variation using data from the other group. K-means algorithm uses an iterative calculation that minimizes the distance of each object to the center of the cluster on all the cluster groups.

\subsection{Image capturing and processing}

The images which will be processed should be in JPG file. To determine the level of contamination on peanuts consisted of several steps, i.e. determination of the average pixel value of the image resulted from image segmentation using image processing algorithm, conversion of the original image into grayscale, determination of contaminated and uncontaminated area, as well as assignment of value toward contaminated and uncontaminated area. Fig.3. shows the flow in identifying the contamination.

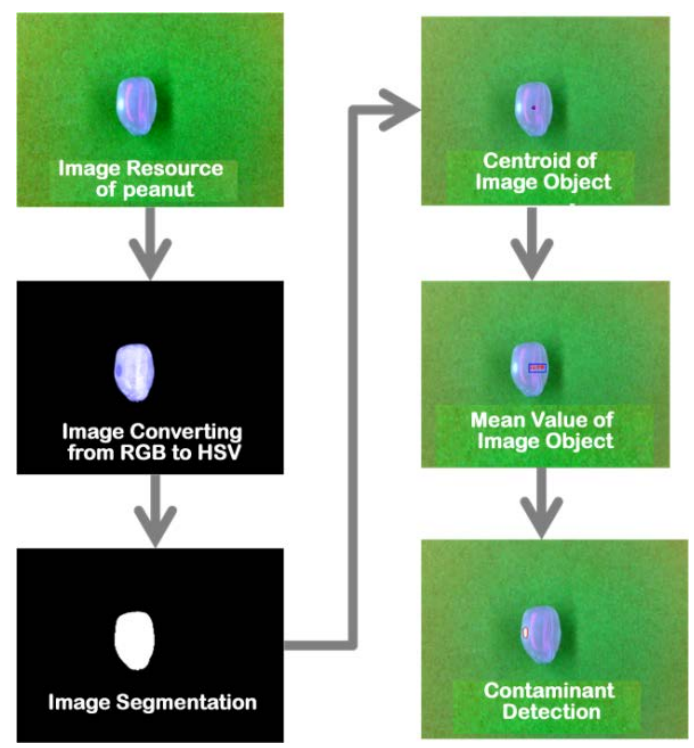

Figure 3 The flow of image processing method to determine contamination in peanuts

\subsection{Analysis of image processing program}

Image processing algorithm shown in Fig. 3 was done on the images captured by a machine vision. The images were then processed using the following steps:

RGB image of samples were converted into HSV format to distinguish color contrast between object and background. To differentiate between object and its background, a segmentation process was applied followed by conversion into binary images. These processes resulted in objects in white color ( 0 binary values) and background in black color (1 binary value). The next process was to determine the center point of identified object to determine the object area. The area was then analyzed to measure the average and deviation standard of pixel values. Contaminated area was identified using a selected threshold value resulted during conversion of RGB to grayscale image. Contaminated and uncontaminated area can be differentiating based on its intensity value. Kmeans clustering algorithms aim at classifying the contaminated and uncontaminated peanuts. 
3. RESULT AND DISCUSSION

\subsection{Results of image processing in} identifying contaminated peanuts

The average pixel values of $R, G$, and $B$ color of contaminated and uncontaminated peanuts were shown in Fig. 4, Fig. 5, and Fig. 6 , respectively.

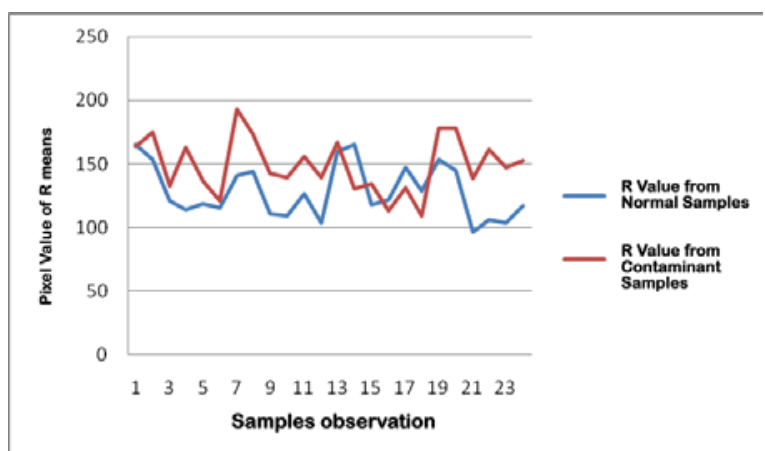

Figure 4 The average pixel value of Red (R) color of contaminated and uncontaminated peanuts

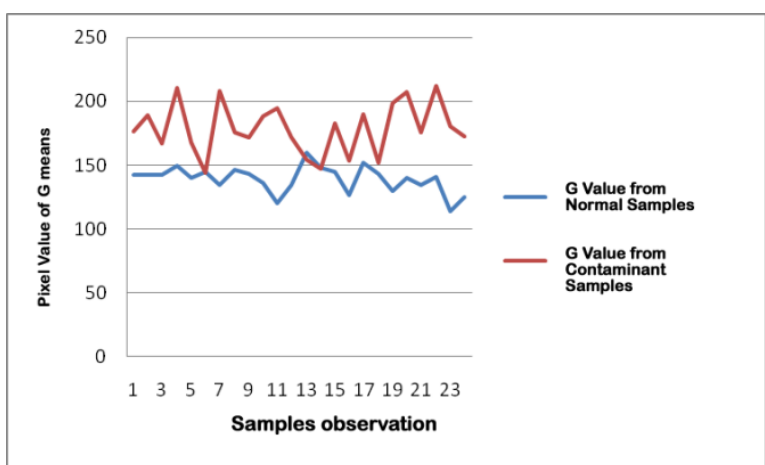

Figure 5 The average pixel value of Green (G) color of contaminated and uncontaminated peanuts

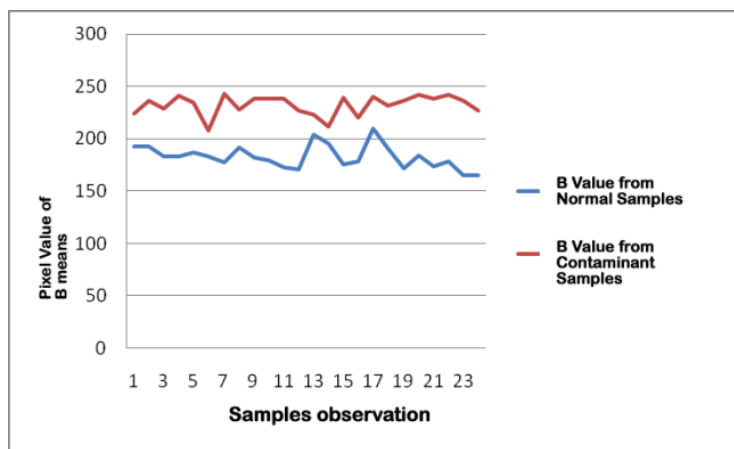

Figure 6 The average pixel value of Blue (B) color of contaminated and uncontaminated peanuts

The previous figures show that there were significant differences in the average of pixel values of $R, G$, and $B$ between contaminated and uncontaminated samples. Therefore, classifications of contaminated and uncontaminated peanuts based on the average of pixel values were used to identify the contamination level using K-means clustering.

\subsection{Results of classification process}

Classification of contaminated and uncontaminated peanuts based on the average pixel value of R,G, B color parameters using $\mathrm{K}$-means algorithm resulted in the center value of R, G, and B of 189, 138, and 224 for uncontaminated peanuts, as well as 162,110 , and 180 for contaminated peanuts, respectively. Fig. 7 shows the results of clustering of contaminated and uncontaminated peanuts using K-means clustering method.

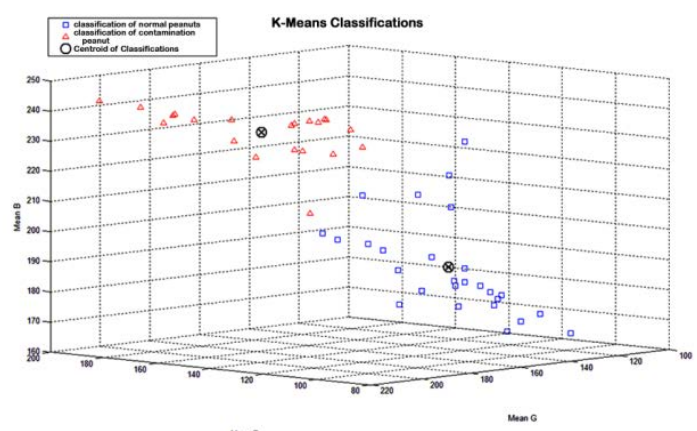

Figure 7 Classification of contaminated and uncontaminated peanuts using K-means clustering method

Fig. 8 shows an analysis of the distance of each point to the cluster center point. It also shows the distance of each point which is closer to the center point of the first cluster compared to the distance of each point of the second cluster indicated by the value higher than 0 . This suggests that the classification based on the image processing clustering of contaminated and uncontaminated peanuts worked well.

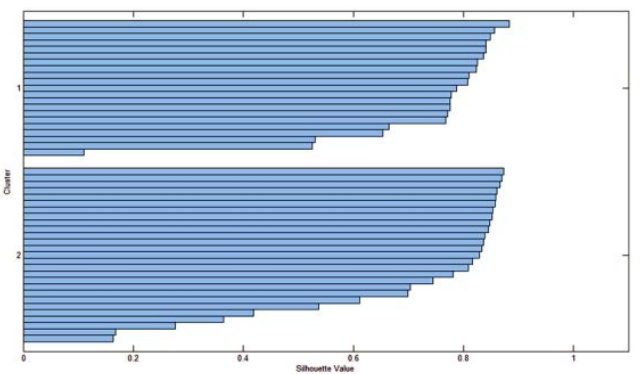


Figure 8 Silhouette analyses on distance measurements of point to the cluster center point

\subsection{Validation of contamination identifica tion method}

Validation was done on 8 new samples comprising of 4 image data of contaminated and 4 image data of uncontaminated samples. Based on the table, the accuracy of detection was $100 \%$ meaning that the performance of machine vision can be used to identify the contaminated and uncontaminated peanuts.

\section{CONCLUSION}

A developed machine vision to identify contamination in peanuts is made from aluminum box, equipped with a camera, a petri for placing the sample, USB connector, UV lamp, and a computer. Image processing methods consisted of analysis of the average color of RGB in the region of interest, convertion of RGB into HSV (Hue Saturation Value), segmentation process, as well as convertion image into grayscale and binary objects in order to obtain the total number of pixels value in the object area so that the mean value of the pixels of the area can be calculated. Classification of contaminated and uncontaminated peanuts based on the average pixel value of R,G, B color parameters using K-means algorithm resulted in the center value of $R, G$, and $B$ of 189, 138, and 224 for uncontaminated peanuts, as well as 162,110 , and 180 for contaminated peanuts, respectively. The accuracy of detection in validation process was $100 \%$ meaning that the performance of machine vision can be used to identify the contaminated and uncontaminated peanuts.

\section{ACKNOWLEDGMENTS}

The authors would like to thank to PHK Institution (PHK I) program from Agricultural Technology Faculty, Gadjah Mada University for supporting research funding. Mrs Niken and Mrs Eri Karuniajati from undergraduated program Agroindustrial Technology Department, Agricultural Technology Faculty, Gadjah Mada University for supporting at laboratory experiment research

\section{REFERENCES}

Bigun, J. 2006. Vision with direction: $a$ systematic introduction to image processing and computer vision, Springer-Verlag Berlin Heidelberg Germany

Faridah, Nopriadi, and Antariksi, A. 2008. Aplikasi mesin vision dalam pendeteksian fertilitas telur, Media Teknik 4.

Gordon, S. G. 2009. Neural Network Pattern Recognition of Photoacou tic FTIR Spectra and KnowledgeBased Techniques for Detection of Mycotoxigenic Fungi in Food Grains, Journal of Food Protecion 2, 221-230

Haff, R. P., Quifiones, B., Swimley, M.S., and Toyofuku, N. 2010. Automatic Image Analysis and Spot Classification for detection of Pathogenic Escherichia coli on Glass Slide DNA Microarrays, Computers and Electronics in Agriculture, 163-169

Kusumaningrum, H., Suliantri, D., Toha, A. D., Putra, S.H, and Utami, A.S. 2010. Cemaran Aspergilus Flavus dan Aflatoksin pada Rantai Distribusi Produk Pangan Berbasis jagung dan Faktor yang mempengaruhinya, Jurnal Teknologi dan industry Pangan 2, 171-176.

Lu, M.C. 1993. Computer Modeling and Simulation Techniques for Computer Visions Problem, Ph.D Dissertation, The Graduate School for Degree of Doctor Philosophy in Electrical Engineering, State University of New York

Lowe, G., Kutcher,S.,R., and Edwards, D. 2003. A Powerful new Light Source for ultraviolet Detection of Scorpions in the Field, Euscorpius-Occasional Publications in Scorpiology 8, 5459

Sebe, N., Cohen, I., Garg, A., and Huang, T. S. 2005, Machine Learning in Computer Vision, Springer Netherlands. 